\title{
ARTICLE OPEN Utilizing genome-scale models to optimize nutrient supply for sustained algal growth and lipid productivity
}

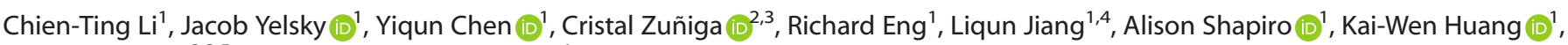
Karsten Zengler ${ }^{2,3,5}$ and Michael J. Betenbaugh ${ }^{1 *}$

Nutrient availability is critical for growth of algae and other microbes used for generating valuable biochemical products. Determining the optimal levels of nutrient supplies to cultures can eliminate feeding of excess nutrients, lowering production costs and reducing nutrient pollution into the environment. With the advent of omics and bioinformatics methods, it is now possible to construct genome-scale models that accurately describe the metabolism of microorganisms. In this study, a genome-scale model of the green alga Chlorella vulgaris (iCZ946) was applied to predict feeding of multiple nutrients, including nitrate and glucose, under both autotrophic and heterotrophic conditions. The objective function was changed from optimizing growth to instead minimizing nitrate and glucose uptake rates, enabling predictions of feed rates for these nutrients. The metabolic model control (MMC) algorithm was validated for autotrophic growth, saving $18 \%$ nitrate while sustaining algal growth. Additionally, we obtained similar growth profiles by simultaneously controlling glucose and nitrate supplies under heterotrophic conditions for both high and low levels of glucose and nitrate. Finally, the nitrate supply was controlled in order to retain protein and chlorophyll synthesis, albeit at a lower rate, under nitrogen-limiting conditions. This model-driven cultivation strategy doubled the total volumetric yield of biomass, increased fatty acid methyl ester (FAME) yield by $61 \%$, and enhanced lutein yield nearly 3 fold compared to nitrogen starvation. This study introduces a control methodology that integrates omics data and genome-scale models in order to optimize nutrient supplies based on the metabolic state of algal cells in different nutrient environments. This approach could transform bioprocessing control into a systems biology-based paradigm suitable for a wide range of species in order to limit nutrient inputs, reduce processing costs, and optimize biomanufacturing for the next generation of desirable biotechnology products.

npj Systems Biology and Applications (2019)5:33

; https://doi.org/10.1038/s41540-019-0110-7

\section{INTRODUCTION}

Microalgae offer significant opportunities to generate diverse products across many different areas including health products like lutein, ${ }^{1}$ pharmaceutical products like camelid heavy chain only antibodies $\left(\mathrm{V}_{\mathrm{H}} \mathrm{H}\right){ }^{2}$ and energy precursors for biodiesel. ${ }^{3}$ Due to its high growth rate and high lipid content, Chlorella vulgaris has been recognized as a promising candidate for algal biofuel production. ${ }^{4}$ Furthermore, studies have found higher lipid productivity in C. vulgaris under heterotrophic growth conditions or nitrogen starvation. ${ }^{4,5}$ However, the cost of inputs including the source of nitrogen, often in the form of nitrate, as well as the organic carbon source, typically glucose in heterotrophic condition, can have a significant impact on overall productions costs. ${ }^{6}$ In addition, the reduction of growth rate under nitrogen starvation can represent another bottleneck due to the loss of algal biomass.

One approach to overcome these limitations is to optimize the natural cells growth and lipid production by controlling nutrient feeding. For example, one approach is to control glucose concentration within a defined range during algal culture using measurements and simple feedback control algorithms. Previous studies controlled glucose concentration in the range of 5 to $40 \mathrm{~g} /$ $\mathrm{L}$ to reach a high cell density culture, increasing cell density from 6.25 to $117.18 \mathrm{gDW} / \mathrm{L}$ in $32 \mathrm{~h}^{7}$

In order to more effectively control nonlinear biological processes like cell culture, model predictive control (MPC), a model-based control strategy, has been designed as one approach to achieve more finely tuned bioreactor control. ${ }^{8}$ Mathematical equations can be constructed to represent the bioreactor system and nutrient supplies optimized based on the simulations. This strategy has been validated in silico for penicillin fermentation process, biohydrogen production in Cyanothece sp, and biofuel production in algae..$^{9-11}$ It was also tested in Chlorella in a CSTR system for $\mathrm{CO}_{2}$ mitigation and in an open pond system under different light intensities. ${ }^{12,13}$ These MPC approaches typically incorporate empirical kinetic models based on experimental data in order to predict optimal algal growth conditions. Researchers obtain model parameters from experimental measurements of cell growth rate and nutrient consumption rate and construct equations in order to simulate algal growth in the models. Those parameters are often associated with the bioreactor system including volume and dilution rate or reflect external characteristics of the cell including growth rate.

However, these previous efforts typically lack a detailed description of the metabolic characteristics of the algal cells themselves and therefore cannot account for nutrient requirements and accompanying cell compositions. These models, while highly descriptive of growth at the macroscopic level, typically do not include the mathematical framework to describe exactly how specific nutrients such as nitrate and glucose are incorporated within the cellular metabolic framework under different culture conditions. Incorporating cellular metabolic details can enable

\footnotetext{
'Department of Chemical and Biomolecular Engineering, Johns Hopkins University, 3400 North Charles Street, Baltimore, MD 21218, USA. ${ }^{2}$ Department of Pediatrics, University of California, San Diego, 9500 Gilman Drive, La Jolla, CA 92093-0760, USA. ${ }^{3}$ Department of Bioengineering, University of California, San Diego, 9500 Gilman Drive, La Jolla, CA 920930412, USA. ${ }^{4}$ School of Environmental Science and Engineering, Shandong University, No.27 Shanda Nan Road, Jinan 250100, China. ${ }^{5}$ Center for Microbiome Innovation, University of California, San Diego, 9500 Gilman Drive, La Jolla, CA 92093-0436, USA *email: beten@jhu.edu
} 
biotechnologies to more effectively understand and potentially optimize the utilization of nutrients within algal cells during growth and lipid production, and be able to consider changes in algal metabolism for different nutrient input scenarios.

Fortunately, the advent of genome-scale models has enabled the biotechnology community to better understand the allocation and distribution of nutrients to metabolites and biomass. ${ }^{14}$ Genome-scale metabolic models are a system biology tool that represent the metabolism of a cell based on its genomic sequence. In order to reconstruct biological networks into a genome-scale model, metabolic reactions in the form of mass balance equations that integrate nutrient transport, intracellular metabolism, and biomass accumulation are included. ${ }^{15}$ Model constraints are obtained by considering genomics, transcriptomics, proteomics as well as cellular composition information. ${ }^{16}$ Thousands of metabolic reactions are composed as a large stoichiometric matrix $(m \times n)$; followed by flux balance analysis required that is solved in order to identify the flux rates of each reaction. Furthermore, as the model is typically underdetermined, linear programming is incorporated in order to identify an optimal flux solution by maximizing an objective function, typically the biomass production rate. ${ }^{17}$

Genome-scale models have been constructed for a wide variety of industrial relevant species including $E$. coli, $^{18}$ yeast ${ }^{19}$ and mammalian cells. $^{20}$ Indeed, previous research has applied genome-scale models to a variety of applications including microbial strain optimization, ${ }^{21}$ intracellular metabolite pool prediction, $^{16}$ and the discovery of new metabolic reactions. ${ }^{22}$ Recently, our group constructed a genome-scale model for $C$. vulgaris (iCZ843), which provides the most comprehensive representation of the physiology of this organism to date, including 843 genes, 2,294 reactions, and 1,770 metabolites. ${ }^{23}$ This model contains five cellular compartments including the cytoplasm, mitochondrion, chloroplast, thylakoid and glyoxysome, in addition to the extracellular environment, allowing metabolic exchange within and between the different compartments. In addition, corresponding experiments successfully validated model predictions, including the capacity to vary the growth rate of $C$. vulgaris by altering nutrient inputs. Furthermore, the iCZ843 model was used to contextualize metabolomics data over the course of growth, evaluating dynamic changes in the biomass composition under different nutrient conditions, resulting in an updated model of $C$. vulgaris model (iCZ946). ${ }^{16}$

In genome-scale model studies, biomass production is typically set as the objective function in order to drive the optimization in the model and predict cell growth rates. ${ }^{17}$ However, for our metabolic model control (MMC) applications, the primary objective may be the capacity to control nutrient utilizations in order to control inputs that can then be provided based on model predictions. In the current study, growth of C. vulgaris was estimated based on experimental optical density (OD) measurements and then used to predict subsequent growth rates during the exponential phase. Since the primary objective of this study was to optimize the nutrient supply for algal culture, the objective function was instead changed to optimize nutrient flux input, including nitrate or glucose uptake into algal cells. We then applied the genome-scale model in order to improve predictions of the nutrients required for growth in response to different culture conditions. As a result, we demonstrate the capacity to utilize the metabolic model control in order to more effectively and efficiently optimize bioprocessing for the generation of high levels of algal biomass and biofuel precursors for potential applications in biotechnology. More importantly, this framework demonstrates a new avenue for applying genome-scale models as a way to optimize bioprocessing across a wide range of cell lines and potential applications in biotechnology.

\section{RESULTS}

Controlling nitrate addition under autotrophic condition for optimized growth rates

In order to evaluate the MMC approach, model iCZ946-PAT1 was used to control nitrate supply to autotrophic $C$. vulgaris cultures. Model iCZ946-PAT1 was previously constructed based on the biomass composition obtained under phototrophic and nitrogen sufficient conditions (Fig. S1 and Table S1). In the current approach, the growth rate $(\mu)$ was calculated based on the optical density value $\left(\mathrm{OD}_{750}\right)$ taken from experimental data at a previous time point $\left(O D_{t-1}\right)$ and the current time point $\left(O D_{t}\right)$. Then, the growth rate within the model was constrained to the calculated growth value $(\mu)$ and the objective function was changed to the nitrate uptake rate $\left(F_{N}\right)$. Specifically, the model was optimized to calculate the minimum nitrate amount required to sustain this calculated growth rate over a particular time interval (Fig. 1a).

One uncontrolled C. vulgaris culture was cultured with $250 \mathrm{mg} / \mathrm{L}$ nitrate, while three others were cultured with $25 \mathrm{mg} / \mathrm{L}$ nitrate and fed with $80 \%, 100$ and $120 \%$ of the optimal nitrate requirement based on model predictions after $25 \mathrm{mg} / \mathrm{L}$ nitrate was consumed completely in the medium. For example, if the genome-scale model predicted C. vulgaris cultures need $100 \mathrm{mg} / \mathrm{L}$ nitrate to sustain the growth for the next $24 \mathrm{~h}$, we would add $80 \mathrm{mg} / \mathrm{L}$, $100 \mathrm{mg} / \mathrm{L}$, and $120 \mathrm{mg} / \mathrm{L}$ to MMC- $80 \%, \mathrm{MMC}-100 \%$, and MMC$120 \%$ cultures respectively. Based on the culture volume, a specific amount of nitrate was fed to the culture to reach the concentration predicted by the model. All cultures were bubbled with $5 \% \mathrm{CO}_{2}$ in order to make excess carbon source available in culture and therefore make nitrate the main variable affecting the growth rate. The controlled cultures fed with nitrate at $25 \mathrm{mg} / \mathrm{L}$ consumed all the nitrogen source by $46 \mathrm{~h}$. Genome-scale metabolic model control was then applied to calculate the subsequent nitrate supply needed at $46,70,94,118,142,150$, and $166 \mathrm{~h}$ (see arrows) (Fig. 1a, b). Eventually, the uncontrolled C. vulgaris cultures consumed all $250 \mathrm{mg} / \mathrm{L}$ nitrate by $182 \mathrm{~h}$ and the model predictive feeding was stopped after that time point. Measured nitrate concentration was nearly $0 \mathrm{mg} / \mathrm{L}$ in the medium at all the time points after $46 \mathrm{~h}$ for all MMC conditions, indicating that the total nitrate supplied to the medium was transported or consumed completely into the cell.

Nitrate was added to all the three MMC cultures at 46, 70, 94, $118,142,150$, and $166 \mathrm{~h}$ to reach a total amount available of $170 \mathrm{mg} / \mathrm{L}, 220 \mathrm{mg} / \mathrm{L}$, and $250 \mathrm{mg} / \mathrm{L}$ over the entire duration for the $80 \%, 100 \%$, and $120 \%$ MMC conditions, respectively (Fig. 1C). Even though significantly $<250 \mathrm{mg} / \mathrm{L}$ nitrate was fed to the $80 \%$ and $100 \%$ MMC cultures $(P \leq 0.05)$, growth rates comparable to the bulk-fed group were achieved in the $100 \%$ MMC cultures (Fig. 1d). All four cultures reached $\mathrm{OD}_{750}=2.2$ in $182 \mathrm{~h}$, after which algae entered a nitrogen starvation stage when the MMC feeding was stopped. As displayed by the $120 \%$ MMC condition, even though cells took up all of the nitrate supplied to the medium, feeding an amount of nitrate higher than predicted by the genome-scale model did not benefit algal growth in nitrogen replete or nitrogen depleted conditions (Fig. 1d). This result was further supported by the growth rate obtained for the bulk-fed $250 \mathrm{mg} / \mathrm{L}$, which was similar to that obtained for $100 \%$ MMC culture. Even though the bulk-fed and the MMC 120\% group consumed $22 \%$ and $14.5 \%$ more nitrate than the $100 \%$ MMC group respectively, all three groups exhibited nearly comparable growth rates (Table S2, Fig. 1c, d). However, supplying $80 \%$ of the nitrate amount predicted by the model resulted in a slower growth rate especially after $241 \mathrm{~h}(P \leq 0.05)$ (Fig. 1d and Table S2). The slow growth rate of the $80 \%$ MMC group and unimproved growth rate of $120 \%$ MMC group indicate that the genome-scale model can predict the optimal nitrate amount required for $C$. vulgaris growth.

In addition, we also performed an experiment to show that by incorporating real-time measurements, this MMC approach help 
a

\section{Data Collection}

Measure optical density $\left(\mathrm{OD}_{\mathrm{t},-1} \mathrm{OD}_{\mathrm{t}}\right)$ to calculate growth rate $(\mu)$.

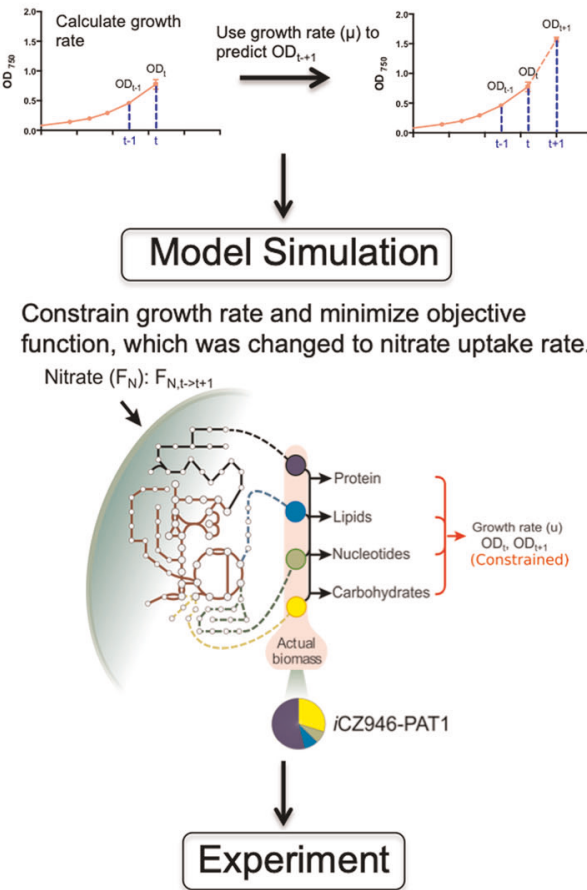

Add nitrate and monitor cell growth in the medium.

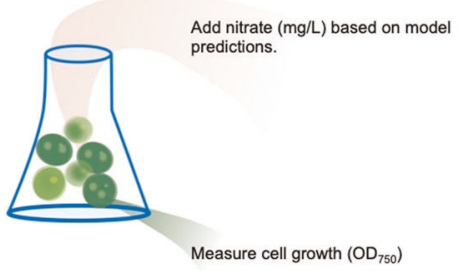

b

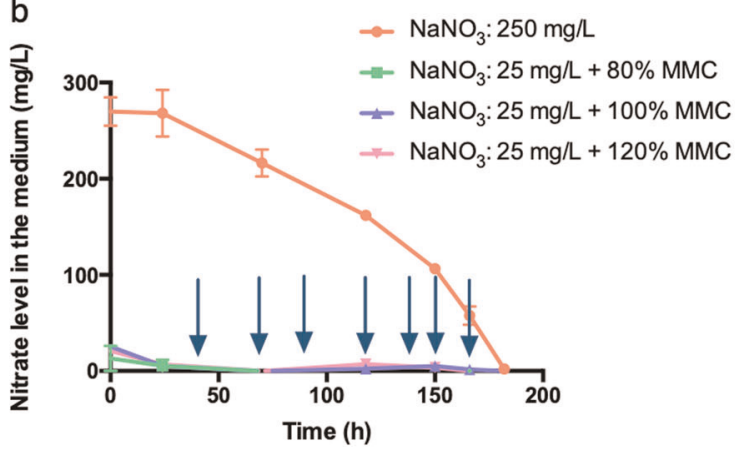

c

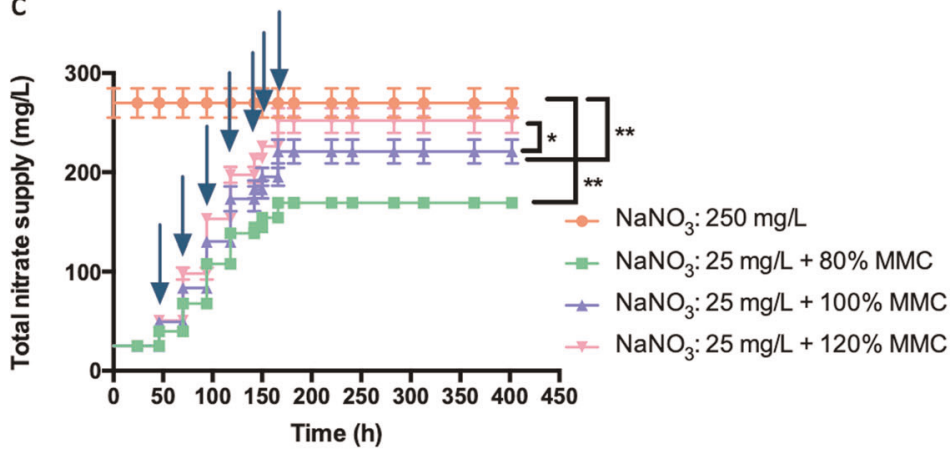

d

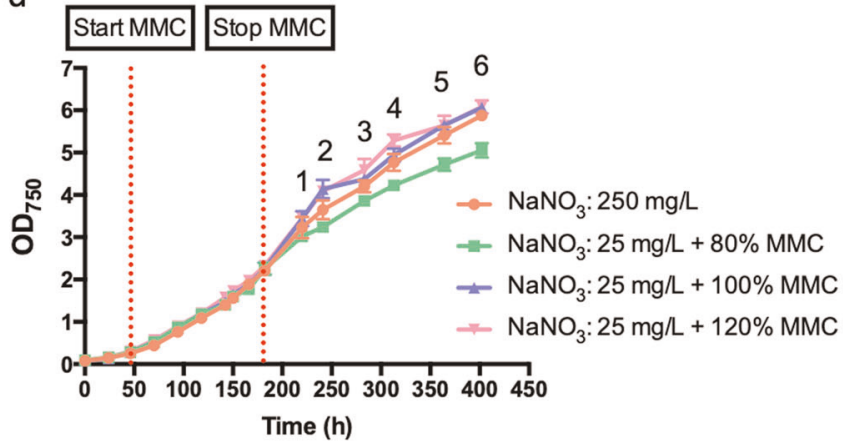

Fig. 1 Metabolic model control under autotrophic conditions. Arrows indicate the feeding time points; a Algorithm of metabolic model control (MMC); b Nitrate level in the medium (mg/L); c Total nitrate supply during the culture (mg/L); $\mathbf{d}$ Growth curve $\left(\mathrm{OD}_{750}\right)$. The $p$-value at time points $1-6$ was provided in Table S2. The data represents the mean \pm SD for $n=3$. ${ }^{*} P \leq 0.05{ }^{* *} P \leq 0.01$

to enhance the performance of algal cultures and also control nutrient supply more efficiently compared with standard approaches based on biological approaches.

In this experiment, C. vulgaris culture was fed with nitrate using 3 different feeding strategies. The control case included an initial loading of $285 \mathrm{mg} / \mathrm{L}$ nitrate with no subsequent feeding. A second case was based on the biological knowledge of the growth rate $\left(0.0137 \mathrm{~h}^{-1}\right)$ from the previous experiment (Fig. 1) to predict the nitrate supply; this nitrate was fed every $12 \mathrm{~h}$, which was actually more often than the MMC case followed (Fig. S2a). For the third MMC conditions, however, we measured the $\mathrm{OD}_{750}$ value every $24 \mathrm{~h}$, and then input the growth rates into our genome-scale model to determine the proper amount to feed every $24 \mathrm{~h}$ for nitrate control in the MMC cultures (Fig. S2a).

The uncontrolled C. vulgaris culture was fed with $285 \mathrm{mg} / \mathrm{L}$ nitrate initially and the nitrate was consumed completely in the media by around $147 \mathrm{~h}$ (Fig. S2b). For the biological based feeding case, the $\mathrm{OD}_{750}$ reached a slightly lower value of 3.9 while also utilizing approximately $285 \mathrm{mg} / \mathrm{L}$ nitrate by experimental completion. However we added a total of only around $233 \mathrm{mg} / \mathrm{L}$ nitrate to the MMC cultures saving $\sim 18 \%$ nitrate while reaching a similar $\mathrm{OD}_{750}$ around 4.3 at $255 \mathrm{~h}$ as the uncontrolled batch experiment
(Fig. S2c, d). By using real-time $\mathrm{OD}_{750}$ measurements, we can predict growth rate and supply nutrients more accurately.

The growth rates of $C$. vulgaris can be controlled under heterotrophy

After successfully applying the genome-scale model iCZ946-PAT1 to control nitrate utilization under autotrophy, a new glucose control feature was included in the model to simulate heterotrophic growth. In this experiment, we applied the iCZ946-HT1 model, which used biomass composition and omics data experimentally determined under heterotrophic and nitrogen sufficient conditions (Fig. S1 and Table S1). By using this growth data, we evaluated the demand of glucose and nitrogen in order to characterize growth conditions. First, the measured optical density $\left(O D_{t-1}, O D_{t}\right)$ was used to calculate the growth rate $(\mu)$ and to constrain biomass accumulation rate in iCZ946-HT1. Next, the glucose uptake rate $\left(F_{G}\right)$ was set as the objective function (Fig. 2a). The model was then optimized to calculate the minimum amount of glucose $\left(\mathrm{F}_{\mathrm{G}, \mathrm{t}-\mathrm{t}+1}\right)$ required to sustain algal growth. Then, glucose uptake rate was constrained using the predicted value and nitrate uptake rate $\left(F_{N}\right)$ was set as a new objective function in 
a
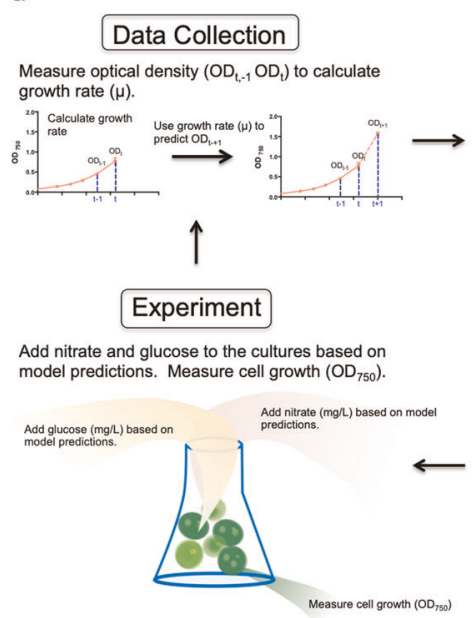

d

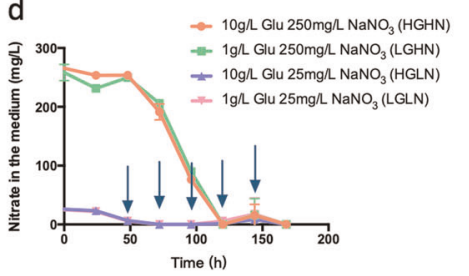

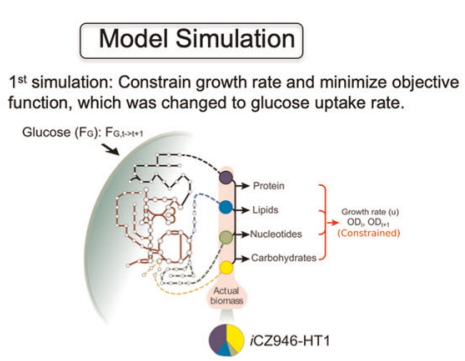

$2^{\text {nd }}$ simulation: Constrain growth rate and glucose uptake rate. Minimize nitrate uptake rate. Nitrate $\left(F_{N}\right): F_{N=t+1}$

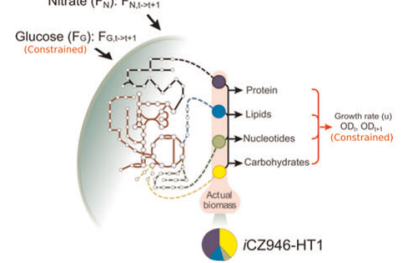

e

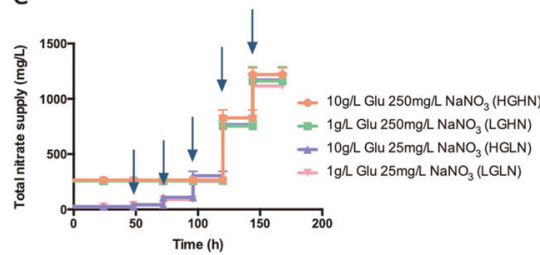

b

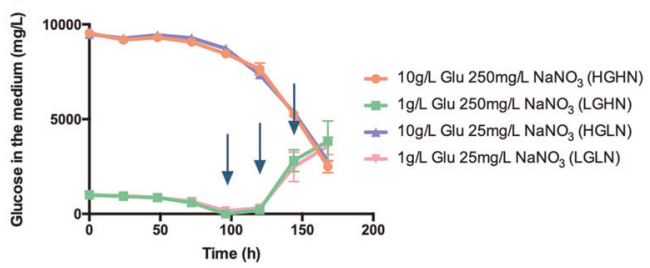

C

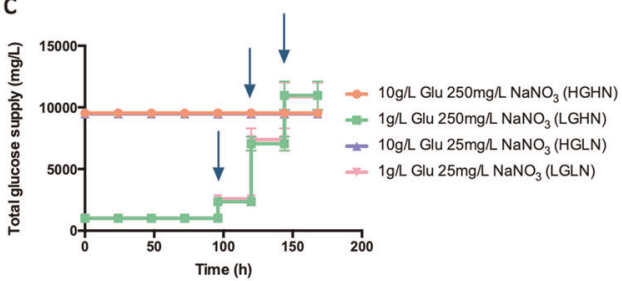

f

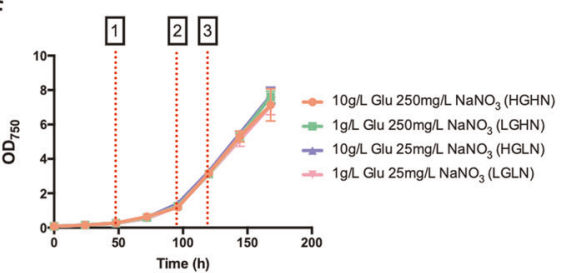

Fig. 2 Metabolic model control under heterotrophic conditions without constraints on glucose uptake rate. Arrows indicate the time points for feeding nutrients. a Algorithm of metabolic model control; b Glucose level in the medium (mg/L); c Total glucose supply during the culture $(\mathrm{mg} / \mathrm{L})$; d Nitrate level in the medium $(\mathrm{mg} / \mathrm{L})$; e Total nitrate supply during the culture $(\mathrm{mg} / \mathrm{L}) ;$ f Growth curve $\left(\mathrm{OD}_{750}\right)$. Point $1: 25 \mathrm{mg} / \mathrm{L}$ nitrate run out; Point 2: $1 \mathrm{~g} / \mathrm{L}$ glucose run out; Point 3: $250 \mathrm{mg} / \mathrm{L}$ nitrate run out. The data represents the mean \pm SD for $n=3$

a subsequent simulation (Fig. 2a). The optimization then yields the amount of nitrate $\left(\mathrm{F}_{\mathrm{N}, \mathrm{t}-\mathrm{t}+1}\right)$ required to sustain algal growth.

This algorithm was performed at combinations of two different levels of glucose (10 g/L [HG], $1 \mathrm{~g} / \mathrm{L}[\mathrm{LG}])$ and two different levels of nitrate $(250 \mathrm{mg} / \mathrm{L}[\mathrm{HN}], 25 \mathrm{mg} / \mathrm{L}[\mathrm{LN}])$. Experimental measurements showed that the low glucose groups (LGHN and LGLN) consumed all the initial glucose within $96 \mathrm{~h}$ (Fig. 2b). Based on the experimental culture volume, specific amounts of glucose were fed to the low glucose groups every $24 \mathrm{~h}$ based on experimental culture volume and model predictions (see arrows in Fig. 2b). The added glucose was nearly consumed between 96 and $120 \mathrm{~h}$ (Fig. 2b). However, after $120 \mathrm{~h}$, the glucose levels started to increase in both LG groups, indicating the glucose was not completely consumed in the culture medium. At $168 \mathrm{~h}, \sim 3800 \mathrm{mg} /$ $\mathrm{L}$ and $3600 \mathrm{mg} / \mathrm{L}$ of glucose was left in LGHN and LGLN groups, respectively (Fig. 2b). A total of around $11,000 \mathrm{mg} / \mathrm{L}$ was fed to both groups over $168 \mathrm{~h}$ (Fig. 2c), resulting in overfeeding after $120 \mathrm{~h}$.

Experimental results indicated that $C$. vulgaris consumed $25 \mathrm{mg} / \mathrm{L}$ nitrate (HGLN and LGLN) and $250 \mathrm{mg} / \mathrm{L}$ nitrate (HGHN and LGHN) by 48 and $120 \mathrm{~h}$. Specific amounts of nitrate were fed to the cultures every $24 \mathrm{~h}$ based on cell growth rate and model predictions for nitrogen uptake rate (Fig. $2 \mathrm{~d}$, e). Unlike the trends observed for glucose supplementation under the heterotrophic conditions, the algae consumed nearly all the nitrate added during each time interval between 48 and $168 \mathrm{~h}$ (Fig. 2d). In this way, the nitrate consumption pattern for $C$. vulgaris was different from the glucose uptake rate over the same period, in which glucose consumption rate did not match model predictions.

Biomass accumulation in all four $C$. vulgaris cultures was tracked as $\mathrm{OD}_{750}$ increased from 0.08 to 7.7 between 0 and $168 \mathrm{~h}$ (Fig. 2f). Initial low nitrate $(25 \mathrm{mg} / \mathrm{L})$ and low glucose $(1 \mathrm{~g} / \mathrm{L})$ levels were exhausted at 48 (time point 1) and $96 \mathrm{~h}$ (time point 2), respectively, and the initial nitrate was exhausted at $120 \mathrm{~h}$ (time point 3), for the high nitrate case $(250 \mathrm{mg} / \mathrm{L})$. The uncoupling of glucose consumption and model predictions at $120 \mathrm{~h}$ suggests a potential bottleneck to glucose consumption at high cell densities of C. vulgaris (Fig. 2b), perhaps due to a limitation in oxygen supply or a limitation in glucose uptake rate that can occur at higher glucose levels. ${ }^{24-26}$ As a result, the current model for heterotrophic growth did not account for these observed bottlenecks to glucose consumption.

Therefore, the MMC algorithm was modified to reflect more accurately the reduced glucose uptake rate in algal culture occurring at higher biomass concentrations. Previously, glucose uptake limitations into Chlorella have been observed and modeled to account for substrate limitation. ${ }^{24,26}$ To account for such limitation in our studies, we obtained an empirical equation describing the relationship between glucose consumption rate and biomass build up rate and this equation was incorporated into the model. The relationship was determined using the integrated value of total biomass produced and glucose uptake rate (Fig. S3a, b). A polynomial regression line accurately fit the trend of glucose uptake rate as a function of biomass accumulation by using GraphPad software $\left(R^{2}=0.947\right)$ (Fig. S3c). This modification was incorporated into MMC to account for the limitation in the cellular glucose uptake rate capability (Fig. 3a). Consideration of both constraints restricts both the growth rate prediction and the glucose uptake rate. By utilizing this new equation to predict glucose uptake rate, we were able to estimate effective growth rates. As a result, we achieved more representative glucose and nitrate uptake rates.

Experimental validation was performed again with four different combinations (HGHN, LGHN, HGLN, and LGLN). C. vulgaris consumed all the initially fed glucose in the LG group $(1 \mathrm{~g} / \mathrm{L}$; LGHN and LGLN) between 61 and $85 \mathrm{~h}$ (Fig. 3b). The MMC algorithm, was used to supply glucose after $61 \mathrm{~h}$. Applying this new constraint on glucose uptake in the model dramatically 
a

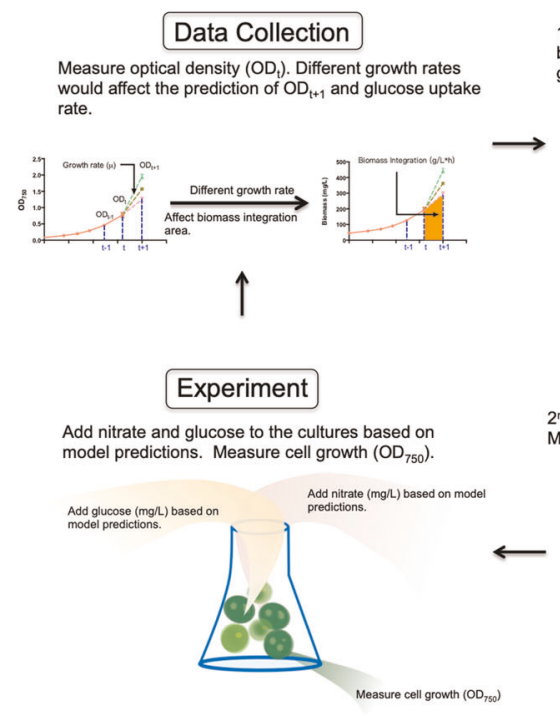

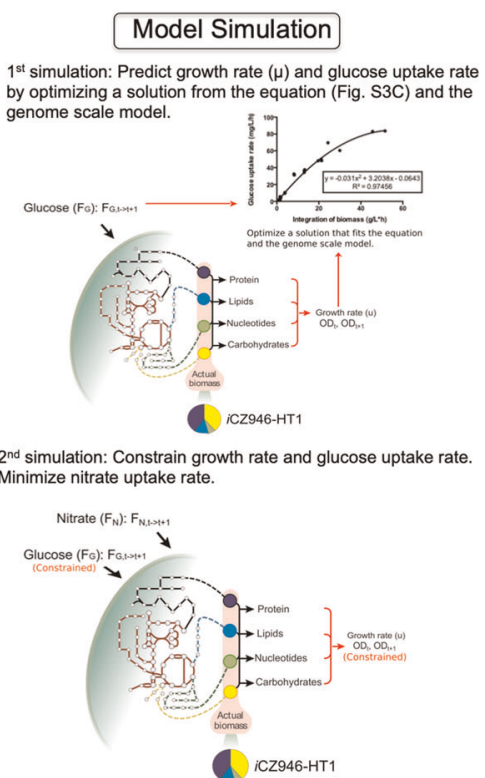

iCZ946-HT1 b

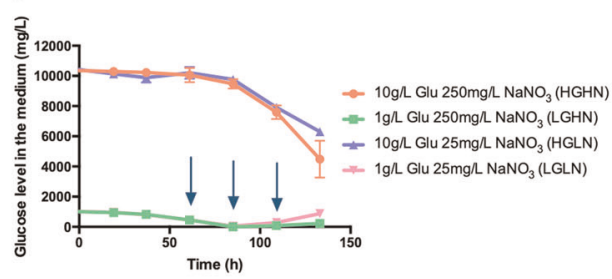

C
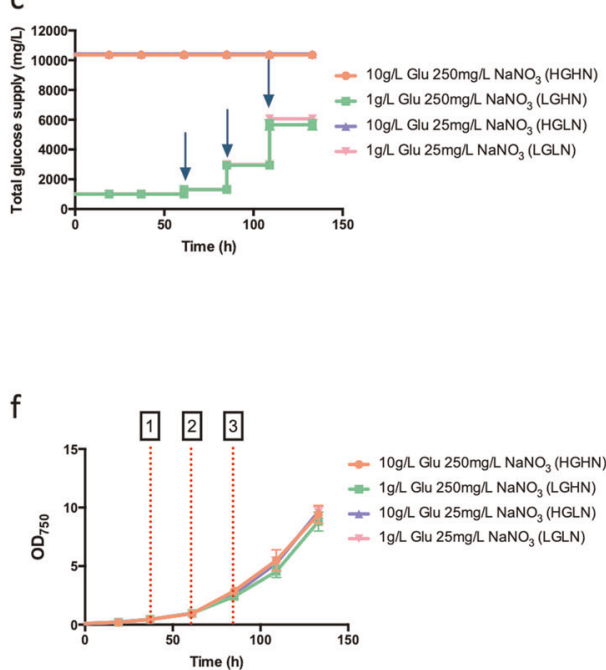

Fig. 3 Metabolic model control in heterotrophic conditions with a constraint on glucose uptake rate. Arrows indicate the time points for feeding nutrients. a Algorithm of metabolic model control (MMC); b Glucose level in the medium (mg/L); c Total glucose supply during the culture (mg/L); d Nitrate level in the medium (mg/L); e Total nitrate supply during the culture (mg/L); f Growth curve $\left(\mathrm{OD}_{750}\right)$. Point $1: 25 \mathrm{mg} / \mathrm{L}$ nitrate run out; Point 2: $1 \mathrm{~g} / \mathrm{L}$ glucose run out; Point 3: $250 \mathrm{mg} / \mathrm{L}$ nitrate run out. The data represents the mean \pm SD for $n=3$

decreased the amount of surplus glucose in the medium to 0-900 $\mathrm{mg} / \mathrm{L}$ in the LG group ( $1 \mathrm{~g} / \mathrm{L} ; \mathrm{LGHN}$ and LGLN) during the period of metabolic model control between 61 and $133 \mathrm{~h}$. Around $5600-6000 \mathrm{mg} / \mathrm{L}$ glucose was fed to the LG group (1 g/L) during the same period of time (Fig. $3 \mathrm{C}$ ). In the HG group ( $10 \mathrm{~g} / \mathrm{L}$; HGHN and HGLN), C. vulgaris only consumed $4100-5800 \mathrm{mg} / \mathrm{L}$ of the initially provided $10,000 \mathrm{mg} / \mathrm{L}$ glucose during the experiment, and left a significant amount of glucose in the medium (Fig. 3b).

Regarding the LN groups ( $25 \mathrm{mg} / \mathrm{L} ; \mathrm{HGLN}$ and LGLN), $25 \mathrm{mg} / \mathrm{L}$ of nitrate was consumed after $37 \mathrm{~h}$ and $250 \mathrm{mg} / \mathrm{L}$ of nitrate was consumed between 85 and $109 \mathrm{~h}$ for the HN groups $(250 \mathrm{mg} / \mathrm{L}$; HGHN and LGHN) (Fig. 3d). Nitrate control was started in the low nitrate group around $37 \mathrm{~h}$ and for the high nitrate group around $85 \mathrm{~h}$. Between $640 \mathrm{mg} / \mathrm{L}$ and $740 \mathrm{mg} / \mathrm{L}$ of nitrate was fed to all four cultures (HGHN, HGLN, LGHN, LGLN) increasing $\mathrm{OD}_{750}$ from 0.08 to the range of 8.8 and 9.7 in $133 \mathrm{~h}$ (Fig. 3e, f).

Modifying biomass composition in genome scale model to control nitrate supply for sustaining algal growth with high lipid productivity

Under nitrogen starvation, C. vulgaris has been found to accumulate high intracellular lipid levels by altering its biomass composition from low fatty acid content $(\sim 10 \%)$ to up to $60 \%$ fatty acid. ${ }^{4}$ C. vulgaris is able to accomplish this shift in biomass composition by recycling intracellular protein back into amino acids, which contributes to lipid synthesis. ${ }^{27}$ However, algae suffer two major drawbacks as a result of this adjustment which are the loss of protein and chlorophyll. ${ }^{28}$ These sacrifices of critical cellular components are likely to lead to an eventual cessation in growth.
Indeed, we observed that C. vulgaris ceases growth during nitrogen starvation when protein content falls below $\sim 10 \%$ (Fig. S4). Our genome scale model was therefore applied to control nitrate supply in order to sustain a protein level around $10 \%$ sufficient for continued algal growth even under stressed conditions.

We previously explored the impact of different nutrient condition changes on the biomass composition and the metabolism of algal cells in a genome scale model. ${ }^{16}$ In the current work, the two different models, iCZ946-PAT1 and iCZ946$\mathrm{HT} 1$, representing autotrophic and heterotrophic cultures, were incorporated into our metabolic model control algorithm and successfully validated the feasibility of nutrient optimization, as shown in Figs. 1 and 3. To account for these changes in algal biomass composition under nitrogen starvation, amino acid content was modified from the previously published autotrophic genome-scale model iCZ946-PAT5 (Table S1), which assumed 16\% of amino acid content in the biomass composition and was constructed using omics data under nitrogen starvation conditions. Our modified models were constructed to include instead $10 \%$ amino acid content (iCZ946-PAT5-10\%AA) and 2\% amino acid content for the biomass composition (iCZ946-PAT5-2\%AA), as shown in Fig. 4a. The nitrate amount calculated for iCZ946-PAT5$10 \%$ AA model should permit algae to synthesize enough protein and preserve sufficient chlorophyll in order to maintain steady algal growth while also potentially yielding a high lipid content under nitrogen starvation metabolism. In contrast, C. vulgaris was expected to cease growing when the nitrate supply was restricted to $2 \%$ as predicted by the iCZ946-PAT5-2\%AA model. 

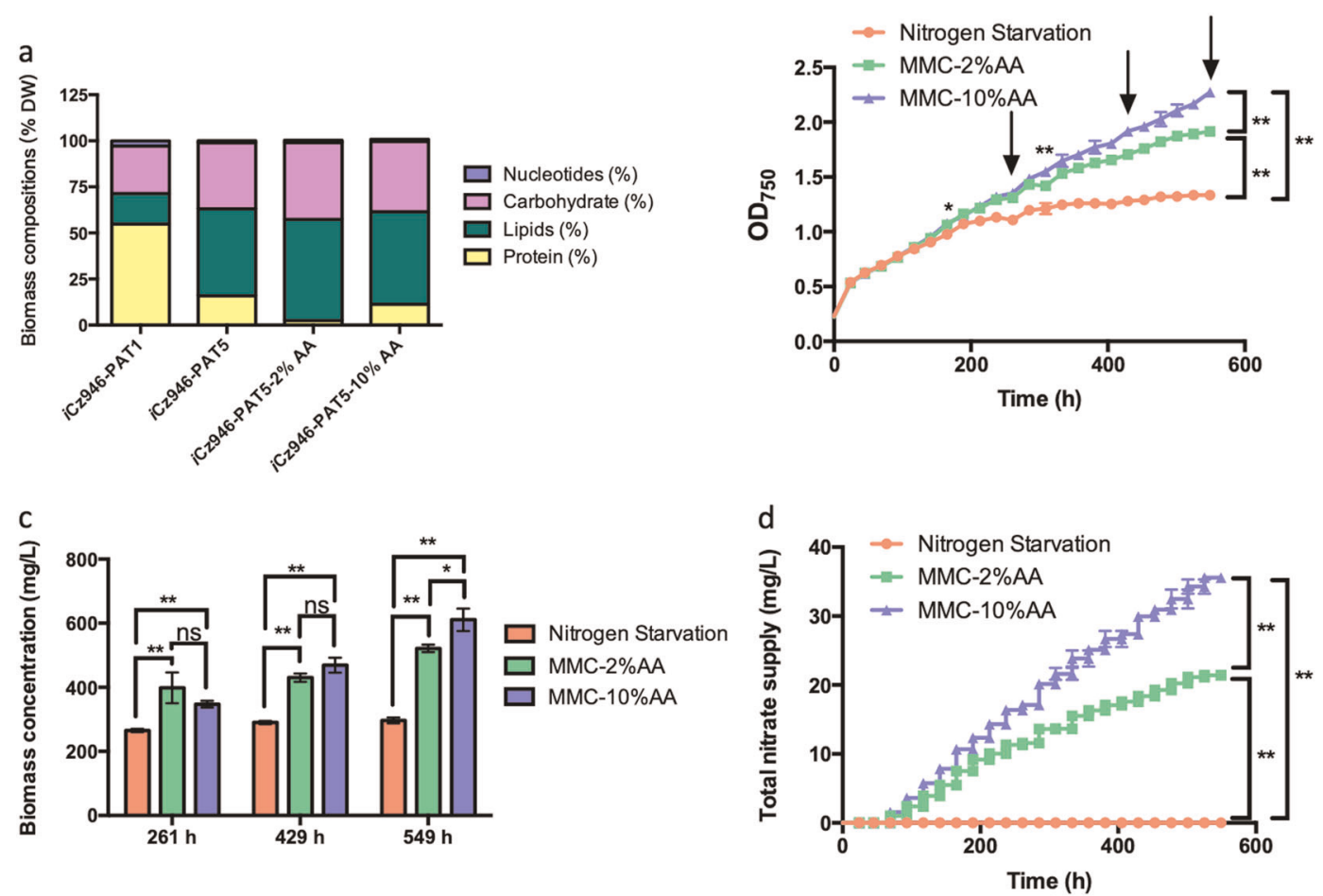

Fig. 4 Metabolic model control under nitrogen limitation. a Biomass compositions in the models (normalized to 100\%); b Growth curve $\left(\mathrm{OD}_{750}\right)$; c Biomass concentration $(\mathrm{mg} / \mathrm{L})$; $\mathbf{d}$ Total nitrate supply during the culture $(\mathrm{mg} / \mathrm{L})$. The data represents the mean $\pm \mathrm{SD}$ for $n=3$. ${ }^{*} P \leq$ $0.05{ }^{* *} P \leq 0.01$

To validate this concept, we again performed an autotrophic experiment in which nitrate was supplemented to cultures every $20-24 \mathrm{~h}$ based on our model prediction (Fig. 4b). One set of two flasks were subjected to nitrogen starvation and two other sets were supplied with a small amount of nitrate based on model predictions using either the iCZ946-PAT5-10\% AA model or iCZ946-PAT5-2\%AA model. For the first $165 \mathrm{~h}$ of growth, all C. vulgaris cultures grew similarly and reached $\mathrm{OD}_{750}=1.0$ (Fig. $4 \mathrm{~b}$ ). However, after $165 \mathrm{~h}, \mathrm{MMC}$ cultures supplemented with nitrate started to grow faster than the nitrogen starvation cultures $(P \leq$ 0.05). At $261 \mathrm{~h}, \mathrm{C}$. vulgaris reached $O \mathrm{D}_{750}=1.1$ for the nitrogen starvation culture, while $\mathrm{OD}_{750}$ increased to 1.3 in both $\mathrm{MMC}-2 \%$ $\mathrm{AA}$ and $\mathrm{MMC}-10 \% \mathrm{AA}$ cultures. At the end of the experiment, around $549 \mathrm{~h}, \mathrm{OD}_{750}$ only increased slightly to 1.3 for the nitrogen starvation culture. In the MMC-2\%AA case, algal growth progressively slowed relative to the $10 \% \mathrm{AA}$ around $309 \mathrm{~h}(P \leq 0.01)$, while still greater than the complete nitrogen starvation case. In contrast, the MMC-10\%AA culture continued to expand over the complete duration of the culture period and reached a final $\mathrm{OD}_{750}$ of 2.3 at $549 \mathrm{~h}(P \leq 0.01)$. These results indicated that an average of $0.06 \mathrm{mg} / \mathrm{L} / \mathrm{h}$ nitrate could support algal growth while targeting a protein content at or near $10 \%$.

Dry biomass was examined at three different time points: $261 \mathrm{~h}$, $429 \mathrm{~h}$, and $549 \mathrm{~h}$, representing periods at which growth slowed significantly for the reduced and depleted nitrate cases (Fig. 4c). Indeed, the nitrogen starvation group, which stopped growing after around $237 \mathrm{~h}$, showed similar biomass yields at its last two time points, ranging from $290 \mathrm{mg} / \mathrm{L}$ to $300 \mathrm{mg} / \mathrm{L}$. The MMC-2\%AA group showed an increase in biomass between all time points, growing from $390 \mathrm{mg} / \mathrm{L}$ at $261 \mathrm{~h}$ to $\sim 430 \mathrm{mg} / \mathrm{L}$ at $429 \mathrm{~h}$ and $520 \mathrm{mg} / \mathrm{L}$ at $549 \mathrm{~h}$. C. vulgaris maintained steady growth under stressed conditions for the MMC-10\%AA condition. The biomass yield steadily increased from $340 \mathrm{mg} / \mathrm{L}$ at $261 \mathrm{~h}$, to $470 \mathrm{mg} / \mathrm{L}$ at $429 \mathrm{~h}$, finally reaching $610 \mathrm{mg} / \mathrm{L}$ at $549 \mathrm{~h}$. The addition of nitrate using the iCZ946-PAT5-10\%AA model facilitated a biomass increase of $30 \%$ at $261 \mathrm{~h}, 61 \%$ at $429 \mathrm{~h}$, and $105 \%$ at $549 \mathrm{~h}$ compared to the complete nitrogen-starvation case $(P \leq 0.01)$. Compared with MMC-2\%AA cultures, the biomass increased $17 \%$ at $549 \mathrm{~h}(P \leq 0.05)$ with no significant difference at $261 \mathrm{~h}$ and $429 \mathrm{~h}$ (Fig. 4c). In total, around $36 \mathrm{mg} / \mathrm{L}$ and $21 \mathrm{mg} / \mathrm{L}$ nitrate were added to the MMC-10\%AA and MMC-2\%AA cultures respectively over the $549 \mathrm{~h}$ cell culture period (Fig. $4 \mathrm{~d}$ ). The reduction in growth rate after $309 \mathrm{~h}$ and biomass at $549 \mathrm{~h}$ in the MMC-2\%AA cultures suggested that the supplied nitrate in MMC-2\%AA condition was insufficient to maintain growth in the late stages of cultivation, confirming the need for a higher amino acid content in the model in order to maintain sufficient algal growth.

FAME content and total FAME yield were measured to evaluate the role of using MMC on lipid productivity. As expected, at 261, 429 and $549 \mathrm{~h}$, algae in the nitrogen starvation group accumulated the highest FAME content among the three different conditions: $35 \%$ at $261 \mathrm{~h}, 44 \%$ at $429 \mathrm{~h}$ and $52 \%$ at $549 \mathrm{~h}$ (Fig. 5a-c). Alternatively, at $549 \mathrm{~h}$, the MMC-2\%AA group accumulated $48 \%$ FAME content and the MMC-10\%AA group accumulated $45 \%$ FAME content, which were $4 \%$ and $7 \%$, below the nitrogen starvation case. This slightly decreased FAME content is to be expected, as a greater fraction of algae metabolism was dedicated to maintaining chlorophyll and protein content in the MMC cultures.

Importantly, the overall FAME yield, which incorporates both FAME content and biomass production, exhibited a different accumulation pattern. While the nitrogen starvation group yielded $175 \mathrm{mg} / \mathrm{L}$ at $549 \mathrm{~h}$, the MMC-2\%AA and MMC-10\%AA group provided $275 \mathrm{mg} / \mathrm{L}$ and $281 \mathrm{mg} / \mathrm{L}$ total FAME yield respectively. Compared with MMC-10\%AA conditions, the slower growth rate at $549 \mathrm{~h}$ did not affect the FAME yield in MMC-2\% AA cultures. Over the three sampling periods, the MMC-10\%AA group displayed an increasingly higher total FAME yield $28 \%$ and $61 \%$ when compared to the nitrogen starvation group at $429 \mathrm{~h}$ and 549 h $(P \leq 0.01)$, respectively. 


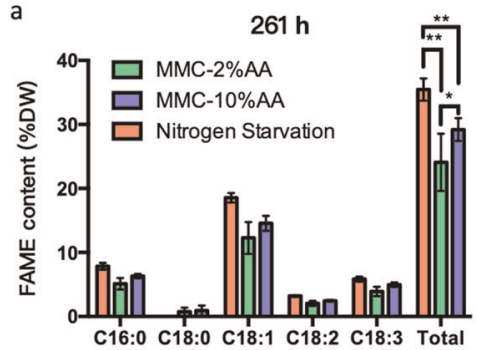

d

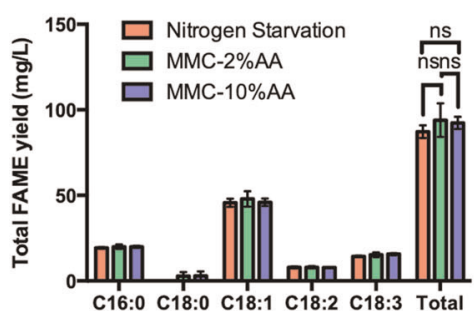

b

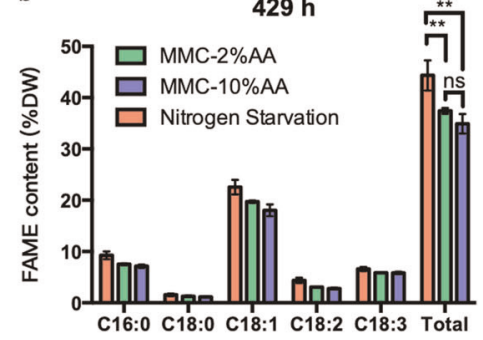

$\mathrm{e}$

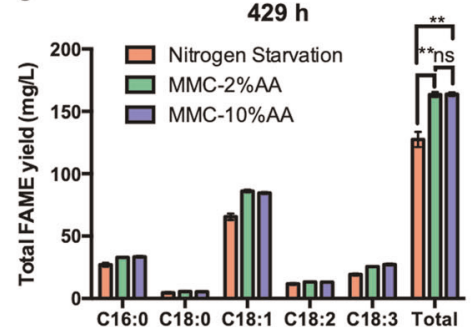

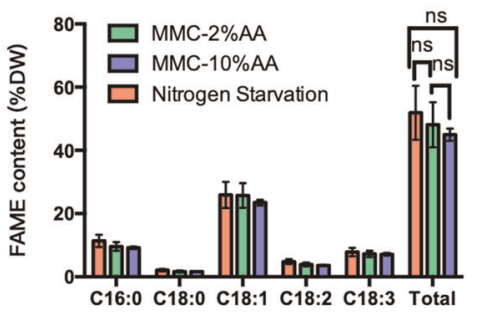

f

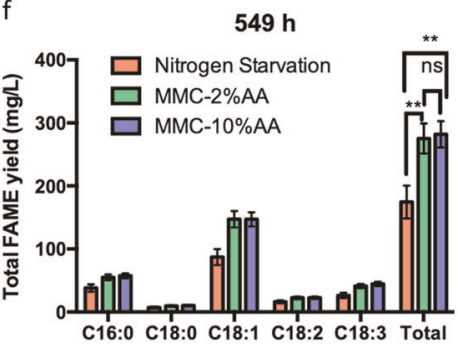

Fig. 5 Fatty acid production at different time points. FAME content (\% DW) at a $261 \mathrm{~h}, \mathbf{b} 429 \mathrm{~h}, \mathbf{c} 549 \mathrm{~h}$. Total FAME yield (mg/L) at d $261 \mathrm{~h}$, e $429 \mathrm{~h}, \mathbf{f} 549 \mathrm{~h}$. The data represents the mean \pm SD for $n=3$. ${ }^{*} P \leq 0.05 * * P \leq 0.01$

Change in biomass constituents under nitrogen starvation and metabolic model control conditions

After successfully controlling $C$. vulgaris growth with high FAME productivity under nitrogen starvation using our genome-scale metabolic model control approach, dry biomass was analyzed to compare the effect of MMC on other biomass constituents. Total chlorophyll yield decreased from $0.99 \mathrm{mg} / \mathrm{L}$ at $261 \mathrm{~h}$ to $0.43 \mathrm{mg} / \mathrm{L}$ at $549 \mathrm{~h}$ for the nitrogen deprivation case (Fig. 6a). Indeed, C. vulgaris is known to degrade the chlorophyll during nitrogen starvation conditions. ${ }^{29}$ Supplying insufficient levels of nitrate to the MMC-2\%AA group also resulted in degradation of chlorophyll from $1.48 \mathrm{mg} / \mathrm{L}$ at $261 \mathrm{~h}$ to $1.31 \mathrm{mg} / \mathrm{L}$ at $549 \mathrm{~h}$. Alternatively, total chlorophyll was maintained between 1.61 to $1.79 \mathrm{mg} / \mathrm{L}$ from 261 to $549 \mathrm{~h}$ in the MMC-10\%AA group. Since overall biomass steadily increased for both MMC groups, the chlorophyll content decreased across all the cultures (Fig. 6b). However, the chlorophyll content was around $0.29 \%$ in MMC-10\%AA cultures, higher than $0.25 \%$ in $\mathrm{MMC}-2 \% \mathrm{AA}$ and $0.14 \%$ in nitrogen starvation $(P \leq 0.05)$. These results suggested that the iCZ946-PAT5-10\%AA model can predict the level of nitrate necessary to maintain substantial chlorophyll content in C. vulgaris for longer periods, sustaining the energy capture capability from sunlight and building up biomass with an elevated fatty acid content in a limiting nitrogen environment.

Since nitrate is a major source of nitrogen for protein synthesis in algae, the protein contents were also measured for all three conditions. At $261 \mathrm{~h}$, protein content for the nitrogen starvation, MMC-2\%AA and MMC-10\%AA cases were around 11-16\% (Fig. $6 c)$. By $549 \mathrm{~h}$, protein content decreased to $6.7 \%, 8.2 \%$ and $12 \%$ under complete nitrogen starvation, MMC-2\%AA and the MMC$10 \%$ AA conditions, respectively. We hypothesized that $10 \%$ protein may be the approximate lower threshold at which algae can maintain metabolic functions and continue growth under nitrogen limitations (See Fig. S4). Indeed, our experiment confirmed this lower threshold, as nitrogen starvation ceased growing around $165 \mathrm{~h}$ and MMC-2\%AA groups growth progressively slowed around $309 \mathrm{~h}$ (Fig. 4b). Meanwhile, the protein content for the MMC-10\%AA group was sustained around $10 \%$ even at $549 \mathrm{~h}$. Previously, protein content has been found to decrease during nitrogen starvation, ${ }^{30}$ but this is the first study to show that continual supplementation of nitrate can maintain the protein content at a reduced level.
In addition to lipids, algae also use starch to store the energy captured from sunlight. Since more chlorophyll was present in the two MMC groups, more energy should be captured in the algal cells, therefore we also determined the starch yield and starch content in this work. We found that under nitrogen starvation conditions, total starch yield was constant between 14 and $15 \mathrm{mg} /$ $\mathrm{L}$ between the three time points (Fig. $6 \mathrm{~d}$ ). In the two MMC groups, the total starch yield increased stably to a higher level than complete nitrate starvation at $261-549 \mathrm{~h}(P \leq 0.01)$ with $42 \mathrm{mg} / \mathrm{L}$ and $49 \mathrm{mg} / \mathrm{L}$ for the MMC-2\%AA and MMC-10\%AA group. Previous studies with $C$. zofingiensis found that starch synthesis was more active during the initial stages of nitrogen starvation, but decreased gradually as nitrogen starvation continued. ${ }^{31}$ Our results indicated that without MMC, cells suppressed starch synthesis from 261 to $529 \mathrm{~h}$. For both MMC groups, our results indicated that starch synthesis driven by sunlight was faster than the degradation due to limitations in the nitrogen levels. The starch content in both MMC groups was also higher than in nitrogen starvation case at most of the time points (Fig. 6e). Total lutein yield was also measured; using the iCZ946-PAT5-10\%AA model resulted in enhanced lutein yields of $195 \%$ and $38 \%$, when compared to the nitrogen starvation group $(P \leq 0.01)$ and the MMC-2\%AA group at $549 \mathrm{~h}(P \leq 0.05)$, respectively (Fig. $6 f)$.

\section{DISCUSSION}

In this work, we demonstrate the application of a genome-scale model for metabolic model control for three different algal culture conditions. Under autotrophic conditions, we validated that this approach could provide an accurate prediction of the amount of nitrate needed without affecting cell growth, saving $18 \%$ of nitrate. Under heterotrophic conditions, we showed that this algorithm could also be applied to calculate multiple nutrient demands including glucose and nitrate while maintaining efficient growth. We also confirmed that this methodology could be applied to cultures under restricted nitrogen conditions. The model was used to predict a sufficient amount of nitrate needed to maintain algal growth rate while targeting a reduced protein content, enabling the cells to maintain fatty acid and lutein productivity. This MMC strategy led to a $61 \%$ increase in total FAME yield and $195 \%$ increase in total lutein yield at $549 \mathrm{~h}$ compared to the nitrate deprivation case. 
a
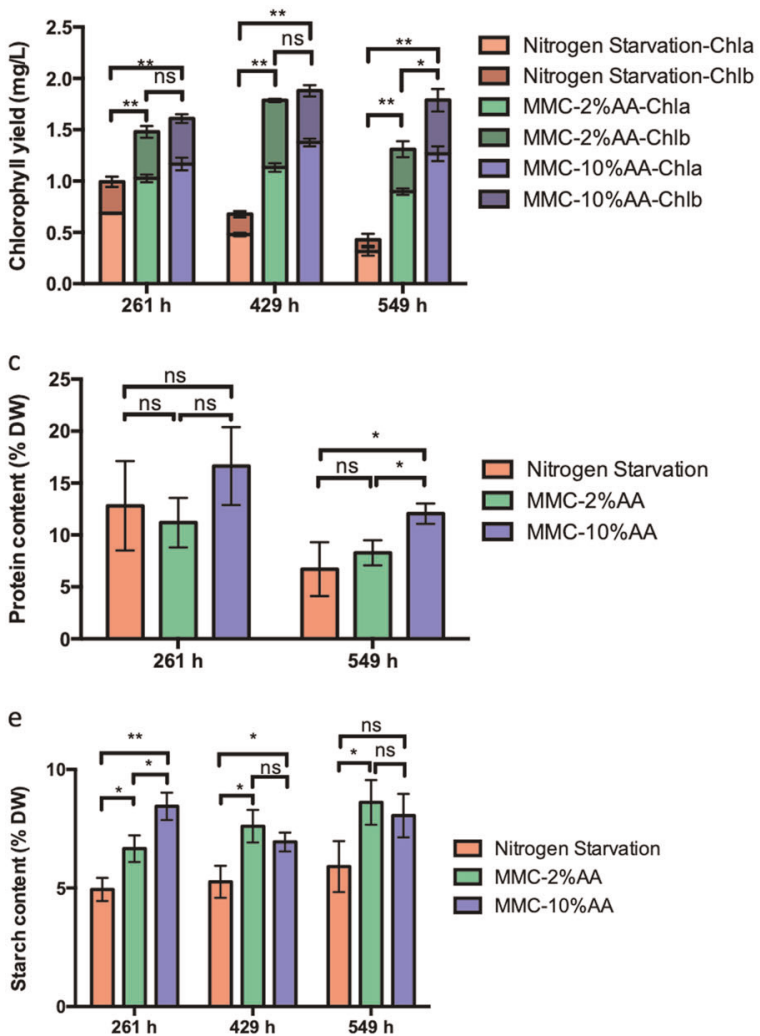

b

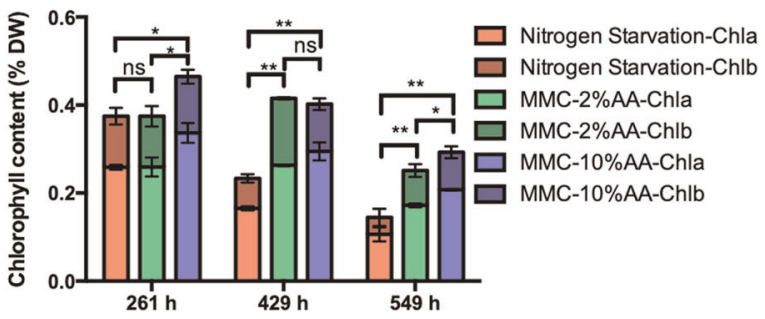

d

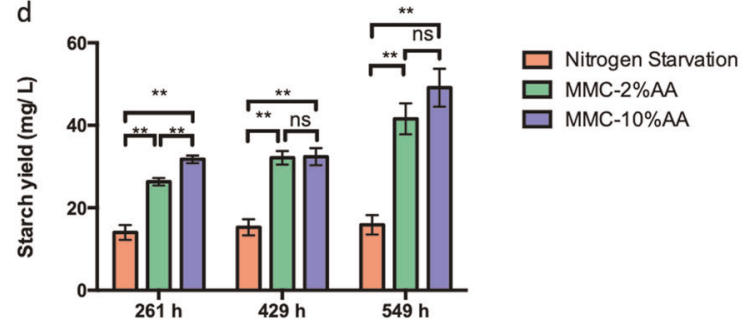

f

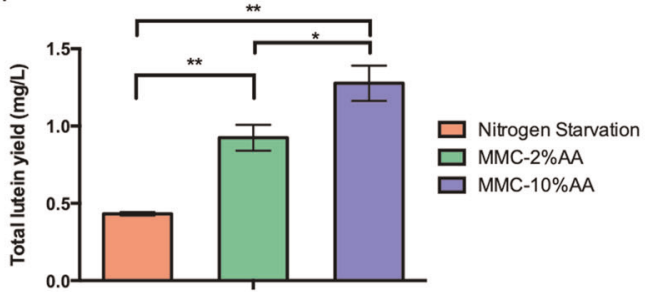

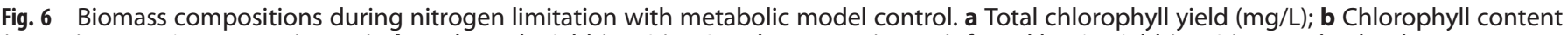

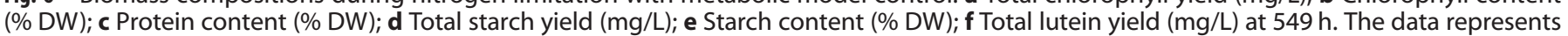
the mean $\pm \mathrm{SD}$ for $n=3 .{ }^{*} P \leq 0.05{ }^{* *} P \leq 0.01$

Interestingly, we observed that even though a theoretical surplus of nitrate was fed for the $120 \%$ MMC condition according to model predictions, the cells still took up all the supplied nitrate experimentally under autotrophic conditions. Comparing the results with the 100\% MMC condition suggested that this nitrate was not used to build more biomass. The phenomena of nitrate uptake rate exceeding nitrogen build up rate in biomass has been indicated previously with our genome-scale model. ${ }^{16}$ Also, Droop and coauthors previously described a phenomena of nitrogen source storage in order to account for algal growth after nitrate is exhausted in the medium. ${ }^{10,32}$ In our metabolic model control approach, nutrient control prediction is driven by growth rate and therefore this method reflects directly the proper nitrate amount needed to build up biomass. It is possible that some of the surplus nitrogen may be secreted out as peptides, proteins or metabolites into the supernatant. In E. coli and mammalian cells, previous studies found that glucose overflow metabolism resulted in acetate and lactate secretion into the medium. ${ }^{33,34}$ Algae can naturally secrete proteins like exozyme as well as fatty acid derivative compounds like diacylglyceryl-N,N,N-trimethylhomoserines (DGTS). ${ }^{35,36}$

Under nitrogen restricted conditions, biomass composition analysis indicated that the iCZ946-PAT5-10\%AA genome-scale model could be applied to successfully limit the nitrate uptake rate while channeling the limiting element into synthesis of chlorophyll and other proteins. The goal was to retain sufficient chlorophyll and other protein content needed to maintain energetic and physiological processes critical to fatty acid production. Indeed, previous researchers found that degradation of chlorophyll decreases light energy conversion efficiency in red algae Porphyridium cruerntum. ${ }^{37}$ Further, in Chlorella, higher amounts of NADPH are required for lipid synthesis under nitrogen deprivation, but somewhat contradictory, photosynthesis from chlorophyll is the major source for NAPDH production. ${ }^{38-40}$ Using MMC to control the nitrate feed supply at reduced levels allowed the cells to continue to grow and accumulate biomass, including chlorophyll, while also synthesizing lipids, resulting in higher overall lipid and starch production rates as compared to the complete nitrogen deprivation case. Consequently, algal growth continued as a result of $\mathrm{MMC}$, even under nitrogen restricted conditions from 261 to $549 \mathrm{~h}$, which was the major fatty acid production stage, leading to higher yields of the fatty acid products compared to complete deprivation. Thus, maintaining sufficient chlorophyll level through limited nitrate feeding in the MMC-10\%AA case allows the algae to support the energy demands needed for robust lipid synthesis in C. vulgaris. In addition, previous studies also found a correlation between lutein content and chlorophyll content in microalgae. ${ }^{41}$ The increase of lutein content in MMC-10\%AA cultures also indicated the importance of optimizing nitrogen supply to sustain chlorophyll and lutein yield under nitrogen-limited conditions. To our knowledge, this is the first time researchers have applied a genome model to increase yields of both bioenergy precursors in the form of fatty acids and health products such as lutein in algal cultures systems under nitrogen-limited conditions.

Similar fatty acid profiles were observed for nitrogen restricted and nitrogen depleted conditions with C18:1 fatty acid as the dominant peak, as shown in Fig. 5a-c. Interestingly, this C18:1 fatty acid content dramatically decreased from $~ 15$ to $18 \%$ DW for these nitrogen restricted conditions to approximately $0.65 \%$ DW under nitrogen replete conditions (Fig. S5). Previous studies found the same trend of increasing C18:1 content in C. vulgaris during a 
shift from nitrogen replete to nitrogen starvation conditions. ${ }^{4,42}$ The presence of a predominance of C18:1 fatty acid in all three cultures of this study (nitrogen depletion and nitrogen restriction) indicates that some levels of cellular response to nitrogen starvation were evident even for the two MMC groups in which the cells were fed with limited amounts of nitrate.

Previously, a study connected a kinetic model with a $C$. reinhardtii genome-scale model to optimize nitrate supply and light intensity for $D$. salina cultures. ${ }^{43}$ In this study, we expanded the capability of our multi-compartment $C$. vulgaris genome-scale models to control multiple nutrients, in this case glucose and nitrate, concurrently for $C$. vulgaris microalgal cultivation studies, including different biomass compositions that can vary as a result of the nutrient inputs. Previously, control has been implemented for algal fed-batch heterotrophic cultures using conventional methods to control glucose concentration within a certain range ${ }^{44}$ or kinetic models to optimize feeding rate. ${ }^{25}$ However, the previous model predictive methods used simple correlations to describe the kinetic interaction between substrate uptake rate and biomass build up rate. In this study, we have demonstrated how genomic information, metabolic networks and biomass compositions can be incorporated to build metabolic model control in order to provide a more precise understanding and control of heterotrophic algal cell cultures. In addition, previous studies observed that a high amount of glucose in the medium can negatively inhibit cell growth in two different Chlorella species. ${ }^{44}$ Our strategy successfully controlled glucose and nitrate at low concentration, which may be particularly useful for scaling up bioreactors in order to limit nutrient input costs and remediate glucose inhibition challenges.

Overall, this study demonstrates the power of building genomescale metabolic models control for nutrient optimization with microbial algal cultures. As data collecting processes evolve, genome-scale models can be implemented into biomanufacturing in order to predict the specific amount of nutrients needed to support algal growth for different conditions and final process objectives as illustrated in supplemental Fig. S6. This systematic control strategy represents a potentially promising method for enhancing biofuel precursor production rates from microalgal cultures while controlling inputs in order to lower overall production costs of algal bioprocessing. A similar genome-based control approach involving restricted nutrient feeding could also be considered for optimizing productivities for other cell factories that generate valuable products during non-growth phases such as yeast production of organic acids ${ }^{45}$ and mammalian cell generation of recombinant proteins. ${ }^{46}$

\section{METHODS}

Algal strain and cultivation conditions

Green microalgae Chlorella vulgaris UTEX 395 was obtained from the Culture Collection of Algae at the University of Texas at Austin and maintained on sterile agar plates $(1.5 \% \mathrm{~W}$-v) containing Bold's Basal Medium (BBM). Liquid cultures were inoculated with a single colony in $12.5 \mathrm{~mL}$ of sterile BBM. Cells were transferred to $100 \mathrm{~mL}$ or $250 \mathrm{~mL}$ glass Fernbach flasks (New Jersey, USA) at $25^{\circ} \mathrm{C}$ using BBM. Autotrophic cultures were grown with different nitrate concentration under fluorescence illumination $\left(30 \mu \mathrm{E} \mathrm{m}^{-2} \mathrm{~s}^{-1}\right)$. Heterotrophic cultures were grown with different glucose and nitrate concentration with $24 \mathrm{~h}$ dark. Nitrogen starvation cultures were grown under BBM without nitrate as nitrogen source. The growth of the cultures was monitored by measuring optical density (OD) at $750 \mathrm{~nm}$. During the metabolic model control, specific amounts of $25 \mathrm{~g} / \mathrm{L}$ nitrate or $20 \mathrm{~g} / \mathrm{L}$ glucose were added manually into the cultures based on model prediction every $20-28 \mathrm{~h}$. All the cultures were done in biological triplicate in this study.
Measurement of algal biomass dry weight and FAME content Liquid cultures were harvested using a high-speed centrifuge (Beckman J2-21, Baltimore, USA) at $4000 \times \mathrm{g}$ for 10 minutes. The pellets were stored at $-80^{\circ} \mathrm{C}$ and lyophilized for $24 \mathrm{~h}$ at $-40^{\circ} \mathrm{C}$ under freeze-dried machine.

FAME production followed the procedure provided by. ${ }^{47}$ FAMEs were analyzed using a Agilent's Gas Chromatography (GC) system with discharge ionization detection equipped with a capillary column (Stabilwax-DA, $30 \mathrm{~m} 0.25 \mathrm{~mm}$ ID, film thickness $0.25 \mathrm{~mm}$ ). GC inlet was set at $250^{\circ} \mathrm{C}$ and the injections were in a volume of $1 \mu \mathrm{L}$. The temperature program started at $50^{\circ} \mathrm{C}$ and then increased to $170^{\circ} \mathrm{C}$ at a rate of $20^{\circ} \mathrm{C}$ $\mathrm{min}^{-1}$, with a plateau for $1 \mathrm{~min}$. After this plateau, the temperature increased from $170{ }^{\circ} \mathrm{C}$ to $220^{\circ} \mathrm{C}$ at a rate of $4^{\circ} \mathrm{C} \mathrm{min}-1$ and then kept constant for 14 minutes. The total analysis time was 35 minutes. Helium was used as carrier gas.

Measurement of lutein yield, starch content, chlorophyll content and protein content

Lutein extraction followed the procedure provided by ${ }^{48}$ The dried algae pellets $(5-10 \mathrm{mg})$ were homogenized using a mortar and pestle with $4 \mathrm{~mL}$ extraction solvent, the mixture of dichloromethane $(25 \%)$ and methanol (75\%), for 2 min and 2 times. The extraction solution was centrifuged at $10000 \times \mathrm{g}$ for $10 \mathrm{~min}$ and kept in dark in $-20^{\circ} \mathrm{C}$. The solution was filtered before HPLC analysis. The mobile phases are eluent A (dichloromethane: methanol: acetonitrile: water, 5.0:85.0:5.5:4.5, v/v) and eluent B (dichloromethane: methanol: acetonitrile: water, 25.0:28.0:42.5:4.5, v/v).

Starch content in dry biomass was analyzed using an assay kit (K-TSHK, Megazyme). Starch in dried algae pellets were hydrolyzed into glucose by a-amylase and amyloglucosidase. Then glucose was digested by enzyme hexokinase and glucose-6-phosphate dehydrogenase. After the reaction, the absorbance at $340 \mathrm{~nm}$ was measured.

Chlorophyll content followed procedure provided by. ${ }^{49}$ Chlorophyll in the dry algae pellets was extracted by DMSO and absorbance at $665 \mathrm{~nm}$ and $649 \mathrm{~nm}$ were measured.

Protein content followed procedure provided by. ${ }^{4}$ Dry Biomass was sonicated on ice for $4^{\circ} \mathrm{C}$ for $30 \mathrm{~s} \times 6$ cycles. Lysates were centrifuged at $16,000 \times g$ for $2 \mathrm{~min}$ and the supernatant were analyzed by bicinchoninic acid assay (BCA assay).

\section{Genome scale model simulation for nutrient control}

The iCZ946 model was obtained from. ${ }^{16}$ Biomass composition, RNA-seq and proteomics data were collected previously under photoautotrophic (PA) conditions and heterotrophic $(\mathrm{H})$ conditions. $^{4,50}$ Six sample points were collected to build six different photoautotrophic models (PAT1-PAT6) and five samples were used to construct five different heterotrophic models respectively (HT1-HT5) as described in our previous publication. ${ }^{16}$ Data collected for all models, except PAT1 and HT1, were undertaken during nitrogen depletion conditions (Fig. S1). iCZ946-PAT1 model was applied for nutrient optimization in autotrophic conditions and iCZ946-HT1 model was used for nutrient optimization in heterotrophic conditions. The iCZ946-PAT5-10\%AA and iCZ946-PAT5-2\%AA models were built by changing amino acid composition in iCZ946-PAT5 model. The growth rate $(\mu)$ was constrained in the model and the objective function was changed to minimize nitrate uptake rate $\left(F_{N}\right)$ or glucose uptake rate $\left(F_{G}\right)$. Genome-scale model simulations were performed using the Gurobi Optimizer Version 5.6.3 (Gurobi Optimization Inc., Houston, Texas) solver in MATLAB (The MathWorks Inc., Natick, MA) with the COBRA Toolbox. ${ }^{51}$

\section{DATA AVAILABILITY}

The data that support the findings of this study are available from the corresponding author upon reasonable request.

Received: 6 November 2018; Accepted: 21 August 2019; Published online: 24 September 2019

\section{REFERENCES}

1. Fernández-Sevilla, J. M., Fernández, F. G. A. \& Grima, E. M. Biotechnological production of lutein and its applications. Appl. Microbiol. Biotechnol. 86, 27-40 (2010).

2. Barrera, D. J. et al. Algal chloroplast produced camelid VHH antitoxins are capable of neutralizing botulinum neurotoxin. Plant Biotechnol. J. 13, 117-124 (2015). 
3. Brennan, L. \& Owende, P. Biofuels from microalgae-a review of technologies for production, processing, and extractions of biofuels and co-products. Renew. Sustain. Energy Rev. 14, 557-577 (2010).

4. Guarnieri, M. T. et al. Examination of triacylglycerol biosynthetic pathways via de novo transcriptomic and proteomic analyses in an unsequenced microalga. PLoS ONE 6, e25851 (2011).

5. Rosenberg, J. N. et al. Comparative analyses of three chlorella species in response to light and sugar reveal distinctive lipid accumulation patterns in the Microalga C. sorokiniana. PLoS ONE 9, e92460 (2014).

6. Li, X., Xu, H. \& Wu, Q. Large-scale biodiesel production from microalga Chlorella protothecoides through heterotrophic cultivation in bioreactors. Biotechnol. Bioeng. 98, 764-771 (2007).

7. Doucha, J. \& Lívanský, K. Production of high-density Chlorella culture grown in fermenters. J. Appl. Phycol. 24, 35-43 (2012).

8. Ramaswamy, S., Cutright, T. J. \& Qammar, H. K. Control of a continuous bioreactor using model predictive control. Process Biochem. 40, 2763-2770 (2005).

9. del Rio-Chanona, E. A. et al. Optimal operation strategy for biohydrogen production. Ind. Eng. Chem. Res. 54, 6334-6343 (2015).

10. Bernard, O. Hurdles and challenges for modelling and control of microalgae for $\mathrm{CO}_{2}$ mitigation and biofuel production. J. Process Control 21, 1378-1389 (2011).

11. Ashoori, A., Moshiri, B., Khaki-Sedigh, A. \& Bakhtiari, M. R. Optimal control of a nonlinear fed-batch fermentation process using model predictive approach. $J$. Process Control 19, 1162-1173 (2009).

12. Juneja, A. \& Murthy, G. S. Model predictive control coupled with economic and environmental constraints for optimum algal production. Bioresour. Technol. 250, 556-563 (2018).

13. Tebbani, S., Lopes, F., Filali, R., Dumur, D. \& Pareau, D. Nonlinear predictive control for maximization of $\mathrm{CO}_{2}$ bio-fixation by microalgae in a photobioreactor. Bioprocess Biosyst. Eng. 37, 83-97 (2014).

14. Tibocha-Bonilla, J. D., Zuñiga, C., Godoy-Silva, R. D. \& Zengler, K. Advances in metabolic modeling of oleaginous microalgae. Biotechnol. Biofuels 11, 241 (2018).

15. O'Brien, E. J., Monk, J. M. \& Palsson, B. O. Using genome-scale models to predict biological capabilities. Cell 161, 971-987 (2015).

16. Zuniga, C. et al. Predicting dynamic metabolic demands in the photosynthetic eukaryote Chlorella vulgaris. Plant Physiol., 00605.02017 (2017).

17. Orth, J. D., Thiele, I. \& Palsson, B. Ø. What is flux balance analysis? Nat. Biotechnol. 28, 245 (2010)

18. Reed, J. L., Vo, T. D., Schilling, C. H. \& Palsson, B. O. An expanded genome-scale model of Escherichia coli K-12 (i JR904 GSM/GPR). Genome Biol. 4, R54 (2003).

19. Förster, J., Famili, I., Fu, P., Palsson, B. Ø. \& Nielsen, J. Genome-scale reconstruction of the Saccharomyces cerevisiae metabolic network. Genome Res. 13, 244-253 (2003).

20. Hefzi, H. et al. A consensus genome-scale reconstruction of Chinese hamster ovary cell metabolism. Cell Syst. 3, 434-443. e438 (2016).

21. Burgard, A. P., Pharkya, P. \& Maranas, C. D. Optknock: a bilevel programming framework for identifying gene knockout strategies for microbial strain optimization. Biotechnol. Bioeng. 84, 647-657 (2003).

22. Rolfsson, O., Palsson, B. Ø. \& Thiele, I. The human metabolic reconstruction Recon 1 directs hypotheses of novel human metabolic functions. BMC Syst. Biol. 5, 155 (2011).

23. Zuñiga, C. et al. Genome-scale metabolic model for the green alga Chlorella vulgaris utex 395 accurately predicts phenotypes under autotrophic, heterotrophic, and mixotrophic growth conditions. Plant Physiol., 00593.02016 (2016).

24. Heath, R. L. A constitutive enzyme system for glucose transport by Chlorella sorokiniana. Plant Physiol. 64, 224-227 (1979)

25. Bumbak, F., Cook, S., Zachleder, V., Hauser, S. \& Kovar, K. Best practices in heterotrophic high-cell-density microalgal processes: achievements, potential and possible limitations. Appl. Microbiol. Biotechnol. 91, 31 (2011).

26. Komor, E., Haass, D., Komor, B. \& Tanner, W. The active hexose-uptake system of Chlorella vulgaris: Km-values for 6-deoxyglucose influx and efflux and their contribution to sugar accumulation. Eur. J. Biochem. 39, 193-200 (1973).

27. Chen, H., Zheng, Y., Zhan, J., He, C. \& Wang, Q. Comparative metabolic profiling of the lipid-producing green microalga Chlorella reveals that nitrogen and carbon metabolic pathways contribute to lipid metabolism. Biotechnol. Biofuels 10, 153 (2017).

28. Ördög, V., Stirk, W. A., Bálint, P., van Staden, J. \& Lovász, C. Changes in lipid, protein and pigment concentrations in nitrogen-stressed Chlorella minutissima cultures. J. Appl. Phycol. 24, 907-914 (2012).

29. Mandels, G. R. A quantitative study of chlorosis in Chlorella under conditions of sulphur deficiency. Plant Physiol. 18, 449 (1943).

30. Lv, J.-M., Cheng, L.-H., Xu, X.-H., Zhang, L. \& Chen, H.-L. Enhanced lipid production of Chlorella vulgaris by adjustment of cultivation conditions. Bioresour. Technol. 101, 6797-6804 (2010).
31. Zhu, S. et al. Metabolic changes of starch and lipid triggered by nitrogen starvation in the microalga Chlorella zofingiensis. Bioresour. Technol. 152, 292-298 (2014).

32. Droop, M. R. 25 years of algal growth kinetics a personal view. Bot. Mar. 26 , 99-112 (1983).

33. Basan, M. et al. Overflow metabolism in Escherichia coli results from efficient proteome allocation. Nature 528, 99 (2015).

34. Young, J. D. Metabolic flux rewiring in mammalian cell cultures. Curr. Opin. Biotechnol. 24, 1108-1115 (2013).

35. Liu, L., Pohnert, G. \& Wei, D. Extracellular metabolites from industrial microalgae and their biotechnological potential. Mar. drugs 14, 191 (2016).

36. Kind, T. et al. Qualitative analysis of algal secretions with multiple mass spectrometric platforms. J. Chromatogr. A 1244, 139-147 (2012).

37. Zhao, L.-S. et al. Nitrogen starvation impacts the photosynthetic performance of porphyridium cruentum as revealed by Chlorophyll a fluorescence. Sci. Rep. 7, 8542 (2017).

38. Wu, C., Xiong, W., Dai, J. \& Wu, Q. Genome-based metabolic mapping and $13 \mathrm{C}$ flux analysis reveal systematic properties of an oleaginous microalga Chlorella protothecoides. Plant Physiol. 167, 586-599 (2015).

39. Gopalakrishnan, S., Baker, J., Kristoffersen, L. \& Betenbaugh, M. J. Redistribution of metabolic fluxes in Chlorella protothecoides by variation of media nitrogen concentration. Metab. Eng. Commun. 2, 124-131 (2015).

40. Xiong, W., Liu, L., Wu, C., Yang, C. \& Wu, Q. 13C-tracer and gas chromatographymass spectrometry analyses reveal metabolic flux distribution in the oleaginous microalga Chlorella protothecoides. Plant Physiol. 154, 1001-1011 (2010).

41. Fu, W. et al. Effects of abiotic stressors on lutein production in the green microalga Dunaliella salina. Microb. Cell Factor. 13, 3 (2014).

42. Stephenson, A. L., Dennis, J. S., Howe, C. J., Scott, S. A. \& Smith, A. G. Influence of nitrogen-limitation regime on the production by Chlorella vulgaris of lipids for biodiesel feedstocks. Biofuels 1, 47-58 (2010).

43. Flassig, R. J., Fachet, M., Höffner, K., Barton, P. I. \& Sundmacher, K. Dynamic flux balance modeling to increase the production of high-value compounds in green microalgae. Biotechnol. biofuels 9, 165 (2016).

44. Xiong, W., Li, X., Xiang, J. \& Wu, Q. High-density fermentation of microalga Chlorella protothecoides in bioreactor for microbio-diesel production. Appl. Microbiol. Biotechnol. 78, 29-36 (2008).

45. Finogenova, T. V., Morgunov, I. G., Kamzolova, S. V. \& Chernyavskaya, O. G. Organic acid production by the yeast Yarrowia lipolytica: a review of prospects. Appl. Biochem. Microbiol. 41, 418-425 (2005).

46. Kim, J. Y., Kim, Y.-G. \& Lee, G. M. CHO cells in biotechnology for production of recombinant proteins: current state and further potential. Appl. Microbiol. Biotechnol. 93, 917-930 (2012).

47. Dong, T. et al. Direct quantification of fatty acids in wet microalgal and yeast biomass via a rapid in situ fatty acid methyl ester derivatization approach. Appl. Microbiol. Biotechnol. 99, 10237-10247 (2015).

48. Yuan, J.-P., Chen, F., Liu, X. \& Li, X.-Z. Carotenoid composition in the green microalga Chlorococcum. Food Chem. 76, 319-325 (2002).

49. Sumanta, N., Haque, C. I., Nishika, J. \& Suprakash, R. Spectrophotometric analysis of chlorophylls and carotenoids from commonly grown fern species by using various extracting solvents. Res. J. Chem. Sci. 2231, 606X (2014).

50. Guarnieri, M. T., Nag, A., Yang, S. \& Pienkos, P. T. Proteomic analysis of Chlorella vulgaris: potential targets for enhanced lipid accumulation. J. Proteom. 93, 245-253 (2013).

51. Schellenberger, J. et al. Quantitative prediction of cellular metabolism with constraint-based models: the COBRA Toolboxv2. 0. Nat. Protoc. 6, 1290-1307 (2011).

\section{ACKNOWLEDGEMENTS}

This work was supported by Emerging Frontiers in Research and Innovation program in U.S. National Science Foundation (Grant number: 1332344) and Department of Energy (Grant number: DE-SC0012658). The authors also thank Dr. Ed Bouwer and Steven Chow at the Department of Environmental Health and Engineering, JHU for assistance with analysis using GC-FID.

\section{AUTHOR CONTRIBUTIONS}

C.T.L, J.Y, Y.C, C.Z, K.Z. and M.J.B. contributed to conception and design of the experiment. C.T.L., J.Y., A.S., R.E., Y.C., L.J. and K.W.H. conducted the experiments. C.T.L., Y.C. and M.J.B. analyzed the data. C.T.L., J.Y., C.Z., K.Z. and M.J.B. drafted the manuscript and all authors reviewed it critically for approval of the final version to be submitted. 


\section{COMPETING INTERESTS}

The authors declare no competing interests.

\section{ADDITIONAL INFORMATION}

Supplementary information is available for this paper at https://doi.org/10.1038/ s41540-019-0110-7.

Correspondence and requests for materials should be addressed to M.J.B.

Reprints and permission information is available at http://www.nature.com/ reprints

Publisher's note Springer Nature remains neutral with regard to jurisdictional claims in published maps and institutional affiliations.
Open Access This article is licensed under a Creative Commons Attribution 4.0 International License, which permits use, sharing, adaptation, distribution and reproduction in any medium or format, as long as you give appropriate credit to the original author(s) and the source, provide a link to the Creative Commons license, and indicate if changes were made. The images or other third party material in this article are included in the article's Creative Commons license, unless indicated otherwise in a credit line to the material. If material is not included in the article's Creative Commons license and your intended use is not permitted by statutory regulation or exceeds the permitted use, you will need to obtain permission directly from the copyright holder. To view a copy of this license, visit http://creativecommons. org/licenses/by/4.0/.

(c) The Author(s) 2019 